\title{
DIAGNÓSTICO ANTENATAL DE SÍFILS CONGÉNITA POR PCR EN LÍQUIDO AMNIÓTICO Y SUS POSIBLES APUCACIONES
}

\author{
Masami Yamamoto C. ${ }^{1}$, Luis Lizama M. ${ }^{2}$, Patricia Valenzuela $H^{3}{ }^{3}$, Jorge Carrillo $T^{1}{ }^{1}$, Alvaro \\ Insunza F. ${ }^{1}$, Priscila Prado D. ${ }^{4}$ \\ ${ }^{1}$ Servicio de Ginecología y Obstetricia, Hospital Padre Hurtado. ${ }^{2}$ Laboratorio Bioscan. ${ }^{3}$ Servicio de Neonatología, \\ Hospital Padre Hurtado. ${ }^{4}$ Servicio de Pediatría, Unidad de Infectología, Hospital Padre Hurtado.
}

\section{RESUMEN}

Se presenta un caso clínico de sífilis congénita diagnosticada antenatalmente mediante el uso de la reacción de la polimerasa en cadena (PCR) en líquido amniótico. La PCR permitiría identificar la espiroqueta en diferentes medios, como en sangre, líquido amniótico y líquido céfalo-raquídeo. Deberán desarrollarse nuevos protocolos para poder probar la efectividad de los tratamientos en base a esta técnica diagnóstica.

\section{PALABRAS CLAVE: Sífilis congénita, diagnóstico antenatal, PCR para treponema pallidum}

\section{SUMMARY}

A clinical case of congenital syphilis diagnosed by means of the use of the polymerase chain reaction (PCR) in amniotic fluid. The PCR would allow to identify the treponema in different sites, like in blood, amniotic fluid and cerebrospinal fluid. New protocols will have to be developed to prove the effectiveness of the treatments on the basis of this diagnostic technique.

\section{KEY WORDS: Congenital syphilis, prenatal diagnostic, treponema pallidum PCR}

\section{INTRODUCCIÓN}

La infección materna y fetal por Treponema pallidum es un problema prevalente en el mundo. Las manifestaciones clínicas de la infección congénita van desde su ausencia como acontece en al menos dos tercios de los casos hasta un gran compromiso séptico, incluida la muerte perinatal (1). El diagnóstico de sífilis congénita se asocia a control prenatal deficiente. Las normas ministeriales de control prenatal exigen 2 exámenes de VDRL o RPR, al inicio del control prenatal y en el tercer trimestre e idealmente pruebas de verificación en casos positivos (2).

Esta comunicación tiene por objeto presentar el aporte de la técnica de reacción de la polime- rasa en cadena (PCR) en el diagnóstico antenatal de sífilis congénita.

\section{Caso Clínico}

Primigesta de 18 años, con VDRL negativo en el primer trimestre, consulta por metrorragia y contracciones uterinas a las 32 semanas de amenorrea. Al examen: signos vitales normales, altura uterina adecuada para la edad gestacional, contracciones uterinas 2 en 10 minutos y cuello sin modificaciones. En la región vulvar presentaba una lesión inadvertida por la paciente, indolora, voluminosa, con zonas solevantadas múltiples y bilaterales, con secreción purulenta en la superficie; en la cara medial del labio menor izquierdo se encontró 
lesión ulcerada (Figura 1). Adenopatías inguinales bilaterales. Se realizó registro basal de la frecuencia cardiaca fetal que fue reactivo, y ecografía en la que no se detectaron anomalías morfológicas del feto, la estimación del peso fetal fue 1800 gramos.

Los exámenes en sangre materna mostraron 12.000 leucocitos, VDRL positivo 1/64. Frente al diagnóstico de una sífilis primaria materna se inició tratamiento con Penicilina benzatina 2,4 millones IM por una vez, la paciente no presentó la reacción de Jarisch-Herxheimer. La paciente continuó con contracciones y taquicardia fetal, por lo que se realizó amniocentesis en búsqueda de infección intraamniótica bacteriana. Se obtuvo líquido amniótico turbio, amarillento, con 100 leucocitos/ $\mathrm{mm}^{3}, 50 \mathrm{mg} / \mathrm{dL}$ de glucosa y Gram sin gérmenes. La PCR en líquido amniótico fue positiva para Treponema pallidum (Figura 2). Se inició inducción de madurez pulmonar con dos dosis de betametasona $12 \mathrm{mg} \mathrm{IM}$. Al tercer día la paciente presentó rotura prematura de las membranas, por lo que se indujo el parto. Se obtuvo un recién nacido de 1950 gramos, Apgar 9-9. El RPR de cordón fue reactivo. El recién nacido presentó 27.000 leucocitos con $9 \%$ de baciliformes y VDRL positivo 1/64. La punción lumbar reveló líquido céfalo-raquídeo transparente, proteína de $97 \mathrm{mg} / \mathrm{dL}$, glucosa de $32 \mathrm{md} / \mathrm{dL}, 5$ células $/ \mathrm{mm}^{3}$, VDRL negativo y PCR negativa. La radiografía de tórax mostró un infiltrado bilateral compatible con neumonitis por treponema (Figura 3). El examen radiológico de extremidades no mostró lesiones óseas. No hubo evidencias clínicas ni de laboratorio de hepatitis.

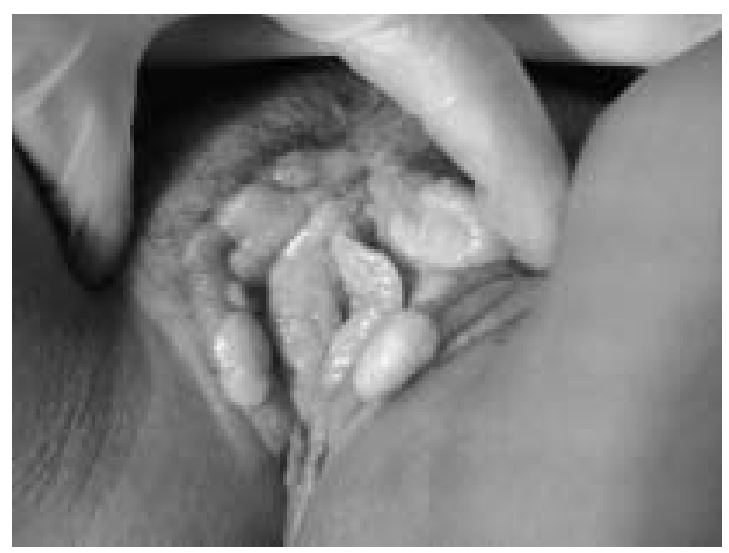

Figura 1. Lesiones vulvares solevantadas bilaterales, con secreción purulenta y una úlcera en la cara medial del labio mayor izquierdo, acompañados de adenopatías inguinales bilaterales. La paciente no se había percatado de las lesiones.

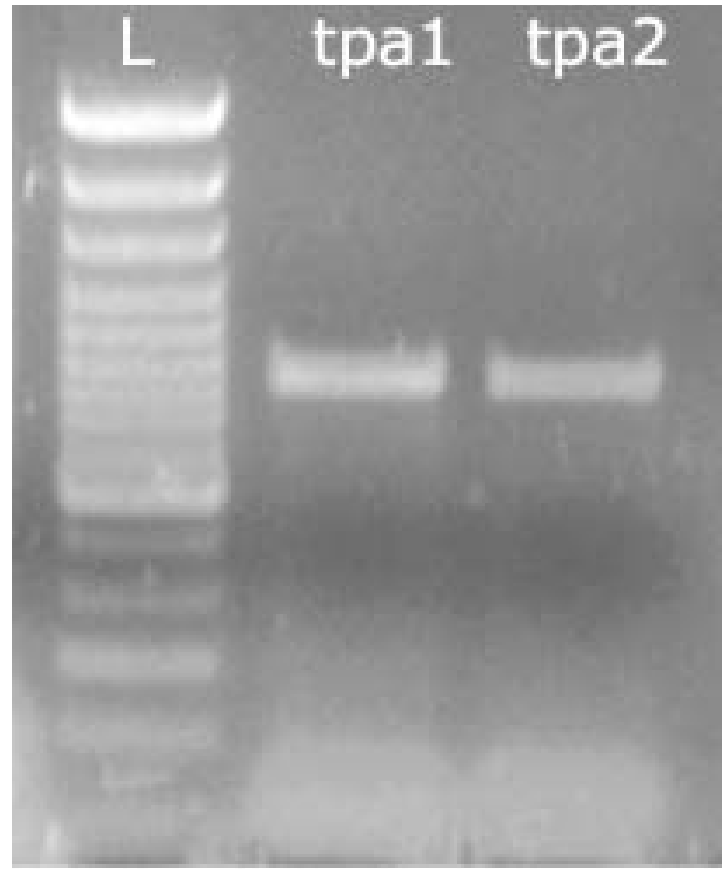

Figura 2. Electoforesis en gel de agarosa. Se muestra la columna de la escala de peso molecular que genera la escala. Se identifica en el líquido amniótico la presencia del gérmen.

El recién nacido fue dado de alta con un tratamiento por 10 días con Penicilina Sódica, 50.000 U/k/día EV.

Técnica de PCR. Las muestras fueron hervidas por 10 minutos a $100^{\circ} \mathrm{C}$ y centrifugadas por

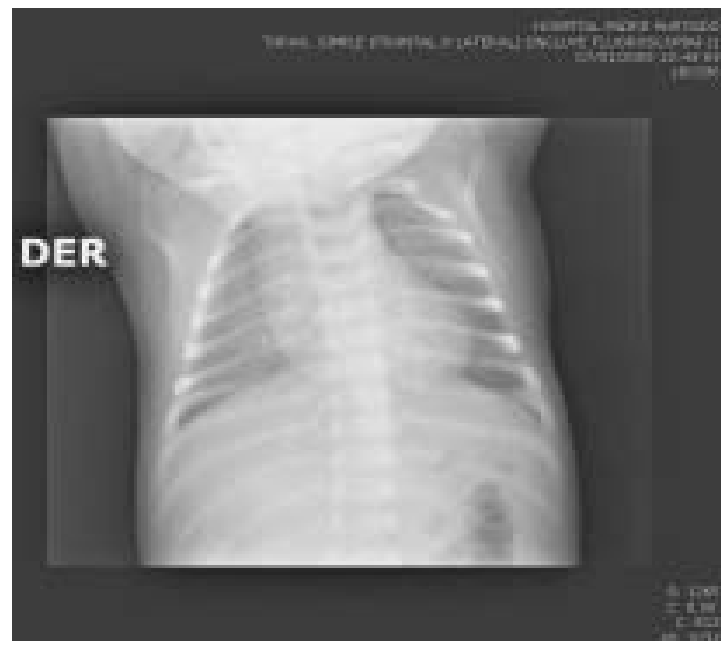

Figura 3. Radiografia de tórax del recién nacido que muestra un infiltrado bilateral compatible con una neumonitis por Treponema. 
5 minutos a $14.000 \mathrm{rpm}$ en una microcentrifugadora. El sobrenadante fue recuperado y congelado a $-20^{\circ} \mathrm{C}$. Cinco microlitros de sobrenadante fueron utilizados para PCR, llevados a un volumen final de $25 \mathrm{~mL}$ conteniendo 0,2 mM dNTP (Promega, Madison, WI), $2 \mathrm{mM}$ de cada primer (IDT, Coralville, IA), $10 \mathrm{mM}$ Tris- $\mathrm{HCl} \mathrm{pH}$ 8.3, 50 $\mathrm{mM} \mathrm{KCl}, 3 \mathrm{mM} \mathrm{MgCl}$, $1 \mathrm{U}$ Taq DNA Polymerase (Gibco BRL, Gaithersburg, MD). La muestra fue tratada a $94^{\circ} \mathrm{C}$ por 5 minutos y sometida a 30 ciclos de amplificación de 1 minuto a $92^{\circ} \mathrm{C}, 1$ minuto a $60^{\circ} \mathrm{C}$ y 1 minuto a $72^{\circ} \mathrm{C}$ con una etapa final de elongación de 5 minutos a $72^{\circ}$ C. Los producto de la amplificación fueron analizados por electroforésis en 1,5\% (wt/vol) gel de agarosa con bromuro de ethidio bromide y fotografiados bajo luz ultravioleta (Figura 2).

\section{DISCUSIÓN}

La incidencia de sífilis congénita en Chile entre los años 1991 y 1995 osciló entre 0,9 y 0,5 por 1000 nacidos vivos, según un estudio realizado con VDRL en sangre de cordón en partos ocurridos en el Servicio de Salud Sur Oriente (3).

La PCR ha sido introducida para el diagnóstico de múltiples infecciones, con una alta sensibilidad y especificidad. La detección de ADN específico ha permitido identificar con una precisión inimaginable una multitud de agentes, sin incurrir a cultivos específicos que muchas veces son engorrosos. En particular, sífilis es un problema de salud pública creciente, y que hasta la fecha no ha sido posible cultivar su agente en medios artificiales. Los métodos confirmatorios se basan en la visualización directa in vivo y en la histología en tejidos afectados $o$ en animales utilizados para cultivo. Por este motivo la introducción de esta técnica en esta enfermedad puede ser de gran beneficio.

Se describe en un estudio con inoculación en conejos que la amplificación del gen de una proteína de membrana específica del treponema tiene una sensibilidad de $0,01 \mathrm{pg}$ de $A D N$, lo que corresponde a un solo microorganismo. El primer estudio que compara la PCR con el cultivo en conejos de treponema en líquido amniótico obtenido de pacientes embarazadas con sífilis fue publicado en 1991 (4).

Se probó la técnica en los animales infectados, siendo positivos en suero, líquido cefalorraquídeo (LCR) y líquido amniótico, pero negativos en animales no infectados (5). También se ha utilizado en las úlceras genitales en hombres y mujeres, con una correlación mayor al 95\% (6) con respec- to a otros exámenes. La técnica de PCR se ha utilizado en el LCR de recién nacidos (7), considerándose en la actualidad como un examen de bajo costo y alta sensibilidad.

La potencial utilidad de esta técnica para el diagnóstico antenatal es múltiple. En casos con sífilis primaria o latente temprana (menor a un año de la infección primaria), la tasa de transmisión vertical es cercana al $100 \%$ (8), sin embargo en casos de sífilis tardía esto baja a $10 \%$. Esto permite pensar que en muchos casos con alergia a la penicilina, este examen permitiría diagnosticar a los casos sin transmisión vertical y tratar a las pacientes solo con eritromicina, y de esta forma, evitar los tratamientos de desensibilización, que son costosos y potencialmente riesgosos.

Un estudio con 253 casos de infección materna demostró que de los 72 recién nacidos con sífilis congénita, un $10 \%$ presentaron muerte fetal (9). La muerte fetal puede ocurrir incluso en casos que las madres recibieron el tratamiento (10), por lo que la demostración del paso transplacentario del Treponema haría indispensable realizar una evaluación del bienestar fetal para disminuir el riesgo de muerte fetal in útero.

Otra indicación posible es el diagnóstico de sífilis en el recién nacido. Hasta la fecha no existe ningún examen con una sensibilidad de 100\% para el diagnóstico de sífilis congénita, y en este contexto la PCR podría tener utilidad clínica. Aproximadamente $80 \%$ de los casos con sífilis congénita son asintomáticos al nacer, por lo que una técnica que permita identificarlos precozmente ayudaría a iniciar el tratamiento precozmente. Dentro de este contexto, la PCR en líquido amniótico, así como en sangre del recién nacido al parto o en el líquido cefaloraquídeo podrían tener utilidad.

Por último, el diagnóstico antenatal por PCR en líquido amniótico podrá certificar los casos de transmisión vertical. Dado la existencia de un tratamiento fácil y de bajo costo en general, la demostración de la afectación antes de iniciar el tratamiento es fundamental para probar su real efectividad.

A pesar de estos posibles beneficios, no todo parece ser tan favorable. La sensibilidad de la PCR en sífilis latente tardía no está estudiada y puede no ser muy alta, ya que es posible que en estos casos la carga bacteriana en líquido amniótico sea tan baja, que la PCR sea falsamente negativa. A su vez, la amniocentesis es un procedimiento que tiene complicaciones como la rotura prematura de las membranas.

En general, la gran potencialidad de esta técnica reside en la dificultad para cultivar al trepo- 
nema. La PCR permitiría identificar la espiroqueta en diferentes medios, permitiendo demostrar su presencia y su potencial patógeno. Nuevos protocolos deberán desarrollarse para poder probar la efectividad de los tratamientos en base a esta nueva técnica diagnóstica.

\section{BIBLIOGRAFÍA}

1. Vial P, Ferres M, Moya F. Infecciones bacterianas durante el período perinatal. En: Obstetricia, Tercera Edición, Editorial Mediterráneo, Pérez A, Donoso E, (eds). Capítulo 46, pp 693-701; Santiago, 1999.

2. Ministerio de Salud, Gobierno de Chile. Guerrero B, Castro R, Biotti M, González R. Control prenatal. En: González R, Gómez R, Castro R, (eds). Guía Perinatal. Capítulo 5, 2003; 43-53.

3. Salvo A. Sífilis congénita: experiencia de 5 años de control sexológico (VDRL) del embarazo, casos clínicos y factores facilitadotes. Rev Chil Dermatol 1998; 14(4): 236-41.

4. Grimprel E, Sanchez PJ, Wendel GD, Burstain JM, McCracken GH Jr, Radolf JD, Norgard MV. Use of Polymerase Chain Reaction and rabbit infectivity testing to detect Treponema pallidum in amniotic fluid, fetal and neonatal sera, and cerebrospinal fluid. J Clin Microbiol 1991; 29(8): 1711-8.

5. Burstain J, Gimprel E, Lukehart S, Norgard M, Radolf J. Sensitive detection of Treponema pallidum by using the Polymerase Chain Reaction. J Clin Microbiol 1991, 29: 62-69.

6. Palmer HM, Higgins SP, Herring AJ y Kinsgton MA. Use of PCR in early Syphillis in the United Kingdom. Sex Transm Infect 2003; 79: 479-483.

7. Michelow IC, Wendel GD Jr, Norgard MV, Zeray F, Leos NK, Alsaadi R, Sanchez PJ. Central nervous system infection in congenital syphilis. N Engl J Med 2002; 346(23):1792-8.

8. Fiumara NJ, Fleming WL, Downing JG et al. The incidence of prenatal syphilis at the Boston City Hospital. N Engl J Med 1952; 247: 48-52.

9. McFarlin BL, Bottoms SF, Dock BS, Isada NB. Epidemia syphilis: maternal factors associated with congenital infection. Am J Obstet Gynecol 1994; 170(2): 535-40.

10. Sheffield J, Sanchez P, Morris G, Maberry M, Zeray F, McIntire DD, Wendel JD Jr. Congenital Syphilis after maternal treatments of syphilis during pregnancy. Am J Obstet Gynecol 2002; 186(3): 569-73. 